\title{
Nonmigrating tidal activity related to the sudden stratospheric warming in the Arctic winter of 2003/2004
}

\author{
D. Pancheva, P. Mukhtarov, and B. Andonov \\ Geophysical Institute, Bulgarian Academy of Sciences, Sofia, Bulgaria \\ Received: 28 October 2008 - Revised: 5 February 2009 - Accepted: 9 February 2009 - Published: 2 March 2009
}

\begin{abstract}
This paper is focused on the nonmigrating tidal activity seen in the SABER/TIMED temperatures that is related to the major sudden stratospheric warming (SSW) taking place in the Arctic winter of 2003/2004. The emphasis is on the nonmigrating diurnal tides observed in the stratosphere and lower mesosphere which is usually accepted to be insignificant in comparison with that in the upper mesosphere and thermosphere. By using different independent spectral methods we found a significant amplification in December-January of the following nonmigrating 24-h tides: zonally symmetric $(s=0)$, eastward propagating with zonal wavenumber 1 (E1), and westward propagating with zonal wavenumbers 2 and 3 (W2 and W3) tides. It has been found that the double peak nonmigrating tidal amplifications located in the stratosphere $(\sim 40 \mathrm{~km})$ and in the lower mesosphere $(\sim 70 \mathrm{~km})$ are a consequence of the maintained hydrostatic relation. By detailed comparison of the evolution and spatial structure of the nonmigrating diurnal tides with those of the migrating diurnal tide and stationary planetary waves (SPWs) evidence for a SPW-migrating tide interaction as a source of nonmigrating tides has been presented. Therefore, the nonmigrating 24-h tides turn out to be an important component of the middle atmosphere dynamics during the major SSW in the Arctic winter of 2003/2004.
\end{abstract}

Keywords. Meteorology and atmospheric dynamics (Middle atmosphere dynamics; Waves and tides) - Space plasma physics (Wave-wave interactions)

\section{Introduction}

The sudden stratospheric warming (SSW) is a dramatic large-scale thermo-dynamical phenomenon in the winter polar region, which strongly affects the middle atmosphere. It

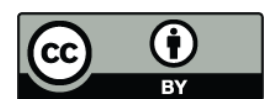

Correspondence to: D. Pancheva (dpancheva@geophys.bas.bg) involves considerable changes of the background wind, temperature, atmospheric waves and distributions of ozone and other chemicals not only at high latitudes. The key mechanism behind the SSW, initially proposed by Matsuno (1971) and now widely accepted, relates to the growth of upward propagating transient planetary waves and their non-linear interaction with the zonal mean flow. The interaction decelerates and/or reverses the eastward winter winds in the stratosphere-mesosphere system and also induces a downward circulation in the stratosphere causing adiabatic heating and an upward circulation in the mesosphere resulting in adiabatic cooling (Liu and Roble, 2002).

The vertical coupling of the stratosphere and mesosphere by planetary waves during SSWs has attracted significant attention recently (Coy et al., 2005; Liu and Roble, 2005; Azeem et al., 2005; Palo et al., 2005, Shepherd et al., 2007; Pancheva et al., 2008a). The middle atmosphere is also latitudinally coupled during SSW events. Mukhtarov et al. (2007) using UKMO reanalyses and mesospheric radar data examined the vertical and latitudinal coupling by large-scale thermo-dynamic anomalies present in the stratosphere and mesosphere of the Northern Hemisphere $(\mathrm{NH})$ during the Arctic winter of 2003/2004. Later utilizing the same data Pancheva et al. $(2007,2008 \mathrm{~b})$ reported that the coupling of the dynamical regimes in the high- and low-latitude stratosphere and mesosphere is accomplished through zonally symmetric (with zonal wavenumber zero) planetary waves present in the zonal wind.

The coupling from the stratosphere to the lower thermosphere (from 30 to $120 \mathrm{~km}$ ) observed in the latitudinal range $50^{\circ} \mathrm{N}-50^{\circ} \mathrm{S}$ during the Arctic winter of 2003/2004 seen in the SABER/TIMED temperature data has been studied recently by Pancheva et al. (2009a, b). The global temperature measurements provided by the SABER/TIMED give an opportunity to examine the tidal activity related to SSWs as well. While the relationship between the planetary wave activity and the SSWs is well studied, the one for the tidal activity, unfortunately, is almost unknown. To the author's

Published by Copernicus Publications on behalf of the European Geosciences Union. 
knowledge there are only a few observational reports, based mainly on the radar measurements in the mesosphere and lower thermosphere (MLT), where the problem for the tidal behavior during the SSWs is slightly touched (Jacobi et al., 2001; Hoffmann et al., 2007).

The present work is focused on the tidal activity related to the major SSW in December 2003-January 2004 which was particularly remarkable because it consisted of a period of nearly two months of polar vortex disruption and a reversed direction of the zonal mean flow observed in the middle and lower stratosphere (Manney et al., 2005). The purpose is to examine whether such a violent event as the major SSW in the Arctic winter of 2003/2004 could affect the nature, temporal evolution and spatial structure of the atmospheric tides. The emphasis is on the tidal activity observed in the stratosphere and lower mesosphere which is usually accepted to be insignificant in comparison with that in the upper mesosphere and thermosphere. The migrating and nonmigrating tides (24- and 12-h tides only) are observed by the SABER/TIMED temperature measurements during the period of 1 October 2003-31 March 2004. An important advantage of the present study is that the tidal results are derived by a data analysis method, described in detail by Pancheva et al. (2009a), where the tides (migrating and nonmigrating) and the planetary waves (zonally travelling and stationary) are simultaneously extracted from the satellite data. In this way a possible distortion of the weaker waves by the stronger ones, as well as some aliasing effects between the tides and SPWs were avoided.

\section{Observations and spectral analysis}

\subsection{SABER temperature data}

The TIMED satellite was launched on 7 December 2001 and the SABER instrument began making observations in January 2002. It measures $\mathrm{CO}_{2}$ infrared limb radiance from approximately $20 \mathrm{~km}$ to $120 \mathrm{~km}$ altitude and the kinetic temperature profiles are retrieved over these heights using a full nonLTE inversion (Mertens et al., 2001, 2004). The retrieval errors, in addition to those associated with instrumental noise, are estimated by Mertens et al. (2001) and they have been found in the range between $1.4 \%$ at $80 \mathrm{~km}$ and $22.5 \%$ at $110 \mathrm{~km}$. In this study, however, the fidelity with which the temperature variations can be determined is primarily important. In this connection, apparent variations introduced into the SABER temperatures by unmodeled variability in the assumed atomic oxygen densities is of prime concern and for this reason the results at the upper altitude of $110-120 \mathrm{~km}$ should be accepted with caution (Forbes et al., 2006).

SABER views the atmosphere $90^{\circ}$ to the satellite velocity vector in a $625 \mathrm{~km}$ and $73^{\circ}$ inclination orbit so that latitude coverage on a given day extends from about $53^{\circ}$ in one hemisphere to $83^{\circ}$ in the other. About every 60 days, the latitude ranges flip as the spacecraft yaws to keep the instrument on the anti-sun side of the spacecraft. In this way high latitude data are available only in 60-day segments, with no information for the 60 days preceding or following. This is the reason not to generate results poleward of $50^{\circ}$. The TIMED orbit precesses to cover $12 \mathrm{~h}$ of local time in each 60 -day yaw period, as ascending and descending data together give almost $24 \mathrm{~h}$ of local time sampling.

Our results are derived from the latest Version 1.07 of the SABER data, which were downloaded from the web site: http://saber.gats-inc.com. While there is a little difference below about $70 \mathrm{~km}$ from $\mathrm{V} 1.07$ and V 1.06, there are substantial improvements for the upper mesosphere and lower thermosphere (Remsberg et al., 2008; García-Comas et al., 2008). We use the temperature data from 1 September 2003 to 30 April 2004, in order to obtain the daily tidal characteristics for the period of time 1 October 2003-31 March 2004 (because it takes SABER 60 days to sample $24 \mathrm{~h}$ in local time of ascending and descending data together). The focus is to study the temporal variability and global spatial structure of the migrating and nonmigrating diurnal and semidiurnal tides. The data were averaged into $5 \mathrm{~km}$ altitude and $10^{\circ}$ latitude bins and each bin was independently analyzed. We work in UT and for each altitude (from 30 to $120 \mathrm{~km}$ at each $5 \mathrm{~km}$ ) and latitude (from $50^{\circ} \mathrm{S}$ to $50^{\circ} \mathrm{N}$ at each $10^{\circ}$ ) the data were arranged in a matrix with 24 columns (this is the longitude with a step of $15^{\circ}$ ) and the number of rows depending on the length of the investigated period of time in hours.

\subsection{Zonal mean SABER temperature in the Arctic win- ter of 2003/2004}

The left plot of Fig. 1 shows the altitude-time cross section of the zonal mean temperature seen in the SABER data at $50^{\circ} \mathrm{N}$ (the highest possible northern latitude for the SABER/TIMED with continuous measurements for the entire winter of 2003/2004) between altitudes 30 and $60 \mathrm{~km}$ for the period of time between 1 October 2003 and 31 March 2004, while the right plot displays the same parameter, but seen in the UK Met Office (UKMO) assimilated temperature data. The SABER result is obtained by performing a linear two-dimensional (time-longitude) least-squares fitting procedure applied to a 3-day window which is moved through the time series with steps of 1 day. The following components are included in the fitting: (i) zonal mean temperature, (ii) linear trend term, (ii) migrating 12- (W2) and 24- (W1) tides, and (iv) the first three modes of the stationary planetary waves (SPWs) (i.e. SPWs with zonal wavenumbers 1, 2 and 3). The sum of the zonal mean and linear trend term is shown in Fig. 1 (left plot).

We note that in order to extract the tides fully (without aliasing effects) we need to use at least a 60-day window (to sample $24 \mathrm{~h}$ in local time by combining ascending and descending data together). A 3-day window is used in this case in order to demonstrate the effect of the major SSW in 

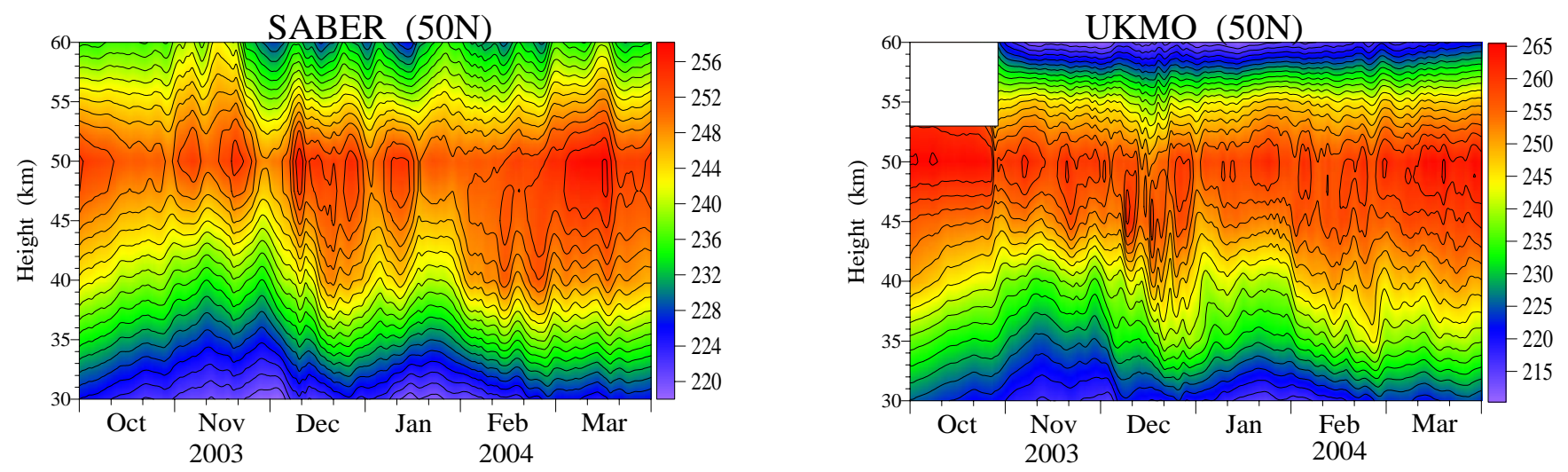

Fig. 1. Altitude-time cross section of the zonal mean temperature seen in the TIMED/SABER data (left plot) and in the UKMO assimilated data (right plot) at $50^{\circ} \mathrm{N}$ for the period of time between 1 October 2003 and 31 March 2004.

December/January on the SABER zonal mean temperature that is surely with time scales shorter than 60 days. As a consequence of using a 3-day window we can expect some aliasing effects on the zonal mean temperatures from the migrating tides because the precession period of the TIMED satellite is long and therefore, over a period of one or a few days, there is little progression of local time. The detailed climatological analysis of the SABER migrating diurnal (Mukhtarov et al., 2009a) and semidiurnal (Pancheva et al., 2009c) tides for the time interval between January 2002 and December 2007 indicated however that in the stratosphere only the migrating diurnal trapped component has nonnegligible and regular behavior with summer values on the average of 4 $5 \mathrm{~K}$ and winter ones of $2-3 \mathrm{~K}$. This means that the evolution of the diurnal migrating tide aliases into the derived zonal mean temperature, shown in the left plot of Fig. 1, but the aliasing effect is of the order of the winter migrating diurnal tide values. The high degree of similarity with the daily UKMO zonal mean temperature result presented in the right plot of Fig. 1, which is not affected by aliasing, however, indicates that the aliasing effect on the SABER zonal mean temperature is insignificant.

The period of time disturbed by the major SSW is clearly outlined in both plots of Fig. 1. A large temperature anomaly composed of a few warm pulses could be distinguished between the beginning of December and middle of January. The onset of the major SSW is around 4 January when the zonal mean zonal wind becomes westward at $10 \mathrm{hPa}$ and at $60^{\circ} \mathrm{N}$ (not shown result). Therefore, the disturbed December-January period of time will be studied in detail later. The main focus will be on the tidal activity possibly related to the major SSW taking place in the middle of the Arctic winter of 2003/2004. A detailed investigation of the planetary wave activity during the same winter seen in the SABER temperatures from the stratosphere to the lower thermosphere has been reported by Pancheva et al. (2009b).

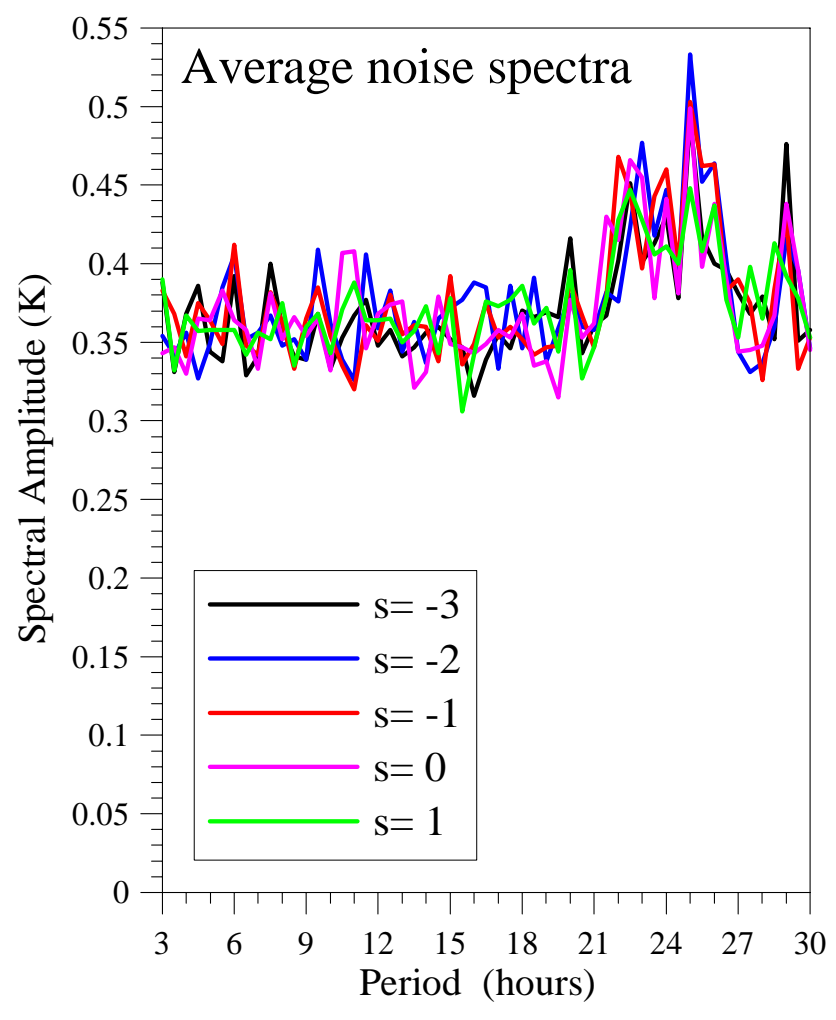

Fig. 2a. Average reference noise spectra for different zonal wavenumber calculated for December/January at latitude $40^{\circ} \mathrm{N}$ and altitude of $40 \mathrm{~km}$ (for details see the text); black color for zonal wavenumber $s=-2$; blue for $s=-2$; red for $s=-1$; magenta for $\mathrm{s}=0$ and green for $s=1$.

\subsection{Spectral analysis}

In order to see if the major SSW affects the nature of the tidal activity we perform a 2-D Lomb-Scargle (LS) periodogram method (Lomb, 1975; Scargle, 1982) only on the temperature data for the disturbed time interval December-January. We 

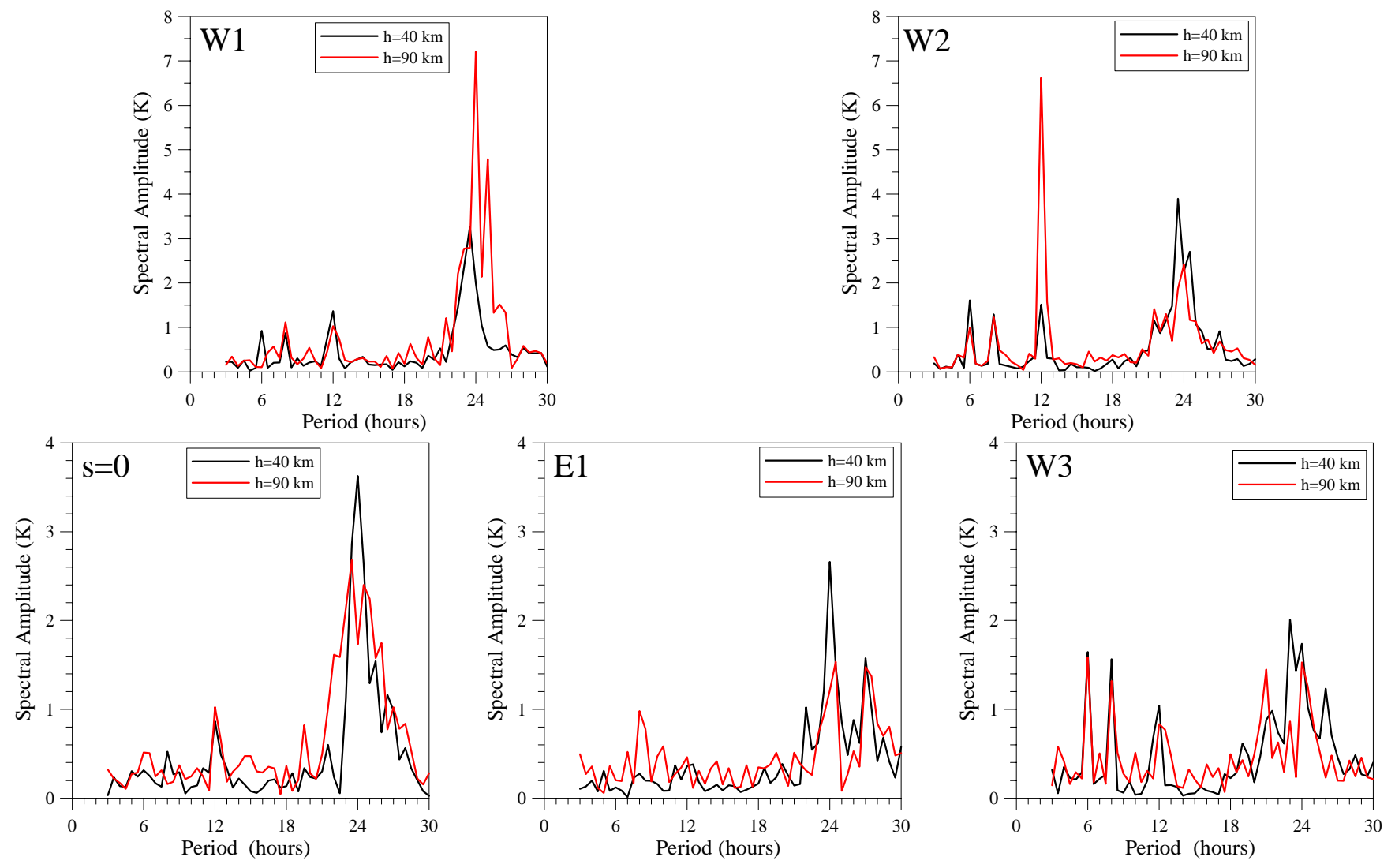

Fig. 2b. Two-dimensional Long-Scargle amplitude spectra calculated from the SABER data for December-January in the period range $3-$ $30 \mathrm{~h}$ and for latitude $40^{\circ} \mathrm{N}$ and altitudes $40 \mathrm{~km}$ (black color) and $90 \mathrm{~km}$ (red color). The spectra presented in the upper row of plots are for the westward propagating tides with zonal wavenumber 1 (W1) and 2 (W2), while those in the bottom row of plots are: the zonally symmetric $(s=0)$ tides (left plot), eastward propagating tides with zonal wavenumber 1 (E1) (middle plot), and westward propagating tides with zonal wavenumber 3 (W3) (right plot).

analyze the $40^{\circ} \mathrm{N}$ temperature data because the data sets (calculated from $35^{\circ} \mathrm{N}$ to $45^{\circ} \mathrm{N}$ ) for different altitudes are complete there. It is important to note that the 2-D LS amplitude spectra are calculated by including in the fitting procedure besides the tides all planetary waves having significant amplitudes in the period of time considered which are studied in detail by Pancheva et al. (2009a, b). These are the SPWs and the zonally travelling planetary waves with periods: $\sim 24,16$, 11 and 5 days with zonal wavenumbers up to 3 .

Because of the satellite data sampling pattern and the variability of the planetary waves during December/January a very important problem in the tidal assessment is how to determine the reference noise level. We investigated in detail the stratosphere levels (30-50 km altitude) where the strong SPWs could alias on the tidal results. For each altitude level and for December/January time interval we generated 100 Gaussian noise datasets with length of 62 days and with data sampling pattern and variance as those of the true SABER measurements (Kong et al., 1998). Then the 2-D LS periodogram was performed on the resulting noise datasets. The reference noise spectrum for each zonal wavenumber was calculated as an average spectrum. The result for the altitude of $40 \mathrm{~km}$ is shown in Fig. 2a, where the noise spectra for different zonal wavenumbers are presented in different colors. The result from this analysis indicated that only because of data sampling pattern and the wave variability in the winter time during December/January all noise spectra revealed a cluster of peaks near $24 \mathrm{~h}$ with amplitudes which do not exceed $0.55 \mathrm{~K}$. We note that the same experiment was done on the 62-day hourly time series but without gaps and then the reference noise spectra did not reveal any prevailing peaks. Therefore the main reason for the observed in Fig. 2a cluster of peaks near $24 \mathrm{~h}$ is the data sampling pattern. The magnitude of the peaks, of course, depends on the data variance. Similar analysis of that shown in Fig. 2a was done on each 60-day window (because a 60-day window is used for extracting the waves) for the considered altitudes and for the entire winter time. On the average the obtained noise amplitudes were between 0.45 and $0.95 \mathrm{~K}$. Therefore, all tidal waves extracted from a given 60-day window with amplitudes larger than $1 \mathrm{~K}$ are accepted as statistically significant. 
As the emphasis in this paper is on the tidal activity observed in the stratosphere, usually accepted insignificant in comparison with that in the MLT region, we compare the amplitude spectra at $40 \mathrm{~km}$ (black line) and $90 \mathrm{~km}$ (red line) altitudes. Figure $2 \mathrm{~b}$ presents the 2-D LS amplitude spectra calculated in the period range $3-30 \mathrm{~h}$ for the tides which are statistically significant. The spectra presented in the upper row of panels are those for westward propagating tides with zonal wavenumber 1 (W1) and 2 (W2). In order to facilitate the comparison these spectra have the same scales (up to $8 \mathrm{~K}$ ) and describe the migrating 12-h (W2) and 24-h (W1) tides, as well as nonmigrating 12-h (W1) and 24-h (W2) tides. They indicate that while the migrating 12 - and 24 -h tides are considerably stronger in the MLT region than those in the stratosphere, the above mentioned nonmigrating tides oppositely are slightly stronger in the stratosphere than in the MLT. The three spectra in the bottom row of panels present the zonally symmetric $(s=0)$ tides (right plot), eastward propagating tides with zonal wavenumber 1 (E1) (middle plot), and westward propagating tides with zonal wavenumber 3 (W3) (left plot). These spectra have the same scales (up to $4 \mathrm{~K}$ ) and describe the nonmigrating 12- and 24-h tides. They reveal that the 24-h nonmigrating tides are considerably stronger in the stratosphere ( $40 \mathrm{~km}$ height) than those in the MLT region ( $90 \mathrm{~km}$ altitude) during the major SSW in December/January.

In order to be sure that the amplification of the nonmigrating 24-h tidal activity in the stratosphere during the major SSW in December/January presented in Fig. 2b is not related to the data analysis method utilized we perform 2-D analogous of the power spectrum obtained from the Fourier transform of the autocorrelation function (Teske, 1974). In our case for each altitude and latitude the SABER temperatures can be presented as:

$\Theta=\Theta(t, l)$

where $\Theta$ is temperature, $t$ - UT time in hours, $l$ - geographic longitude. Then the 2-D autocorrelation function can be presented as:

$\rho_{\Theta}(\tau, \lambda)=\frac{M[\Theta(t, l) z(t+\tau, l+\lambda)]-\{M[\Theta(t, l)]\}^{2}}{M\left[\Theta^{2}(t, l)\right]-\{M[\Theta(t, l)]\}^{2}}$

where $M$ is the expected value operator, $\tau$ and $\lambda$ are the time and longitude lags, respectively.

The power spectrum defined as a Fourier transform of the autocorrelation function can be expressed as:

$F_{\Theta}\left(T, T_{l}\right)=\int_{-\infty}^{\infty} \int_{-\infty}^{\infty} \rho_{\Theta}(\tau, \lambda) \exp \left(-j \frac{2 \pi}{T} \tau-j \frac{2 \pi}{T_{l}} \lambda\right) d \tau d \lambda$

In our case we introduce for convenience a space period in Eq. (2) defined as: $T_{l}=360 / s$, where $s$ is the zonal wavenumber.

Figure 3 presents the power spectrum for $40^{\circ} \mathrm{N}$ latitude and $40 \mathrm{~km}$ altitude calculated from Eq. (2) for the time interval December-January, where $\tau$ and $\lambda$ change from -120 to 120 . The power spectrum is presented in the period range between 3 and $30 \mathrm{~h}$ and zonal wavenumbers between -4 and 4, where the positive (negative) wavenumbers represent the eastward (westward) propagating tides. A careful inspection of Fig. 3 indicates that the results there fully support the results from the 2-D LS amplitude spectra shown in Fig. 2b. The strongest nonmigrating tides are the 24-h zonally symmetric $(s=0)$ and E1 tides followed by the 24-h W2 and W3 tides. The migrating 24-h tide can be distinguished in Fig. 3 as well. It is weaker than the above mentioned nonmigrating diurnal tides with a prevailing period slightly shorter than $24 \mathrm{~h}$; the same feature is also well visible in Fig. $2 \mathrm{~b}$ (upper left panel). Therefore, Figs. $2 b$ and 3 demonstrate that by using two independent spectral methods we obtain one and the same result, which clearly indicates an amplification of the nonmigrating diurnal tides in the stratosphere during the major SSW which takes place in December/January.

\section{Spatial structure of the diurnal tides}

\subsection{Altitude tidal structure at $40^{\circ} \mathrm{N}$}

To study the altitude and latitude structures of the tidal amplitudes observed in the period of time 1 October 200331 March 2004 we have to extract the tides from the SABER data. The method for extracting the waves from the SABER/TIMED temperatures has been described in detail by Pancheva et al. (2009a). For each altitude (from 30 to $120 \mathrm{~km}$ at each $5 \mathrm{~km}$ ) and latitude (from $50^{\circ} \mathrm{N}$ to $50^{\circ} \mathrm{S}$ at each $10^{\circ}$ ) the waves are derived by using a linear twodimensional (time-longitude) least-squares fitting procedure applied to a 60-day window which is moved through the time series with steps of 1 day in order to obtain daily values of the wave characteristics. We note that in order to cover the entire interval of time between 1 October 2003 and 31 March 2004 with daily values of the wave parameters we perform the analysis on an extended interval by adding 30 days to each side (1 September 2003-30 April 2004). The terms included in the data decomposition are as follows: (i) the mean temperature, (ii) a linear trend term responsible for zonally symmetric variations with period longer than 60 days; this term could include a possible effect of the semiannual oscillation (SAO), (iii) travelling planetary waves with zonal wavenumbers up to 3 found by the spectral analysis (with periods: $\sim 24,16,11$ and 5 days), (iv) stationary waves with zonal wavenumbers up to 3 , and (v) 24- and 12-h tides with zonal wavenumbers up to 4 . The main advantage of the simultaneous extraction of the tides and planetary waves from the SABER temperatures consists in avoiding a possible distortion of the weaker waves by the stronger ones, as well as some aliasing effects between the tides and SPWs.

There is widespread understanding about some limitations in getting tidal information from a slowly precessing satellite. That is why the above suggested decomposition 


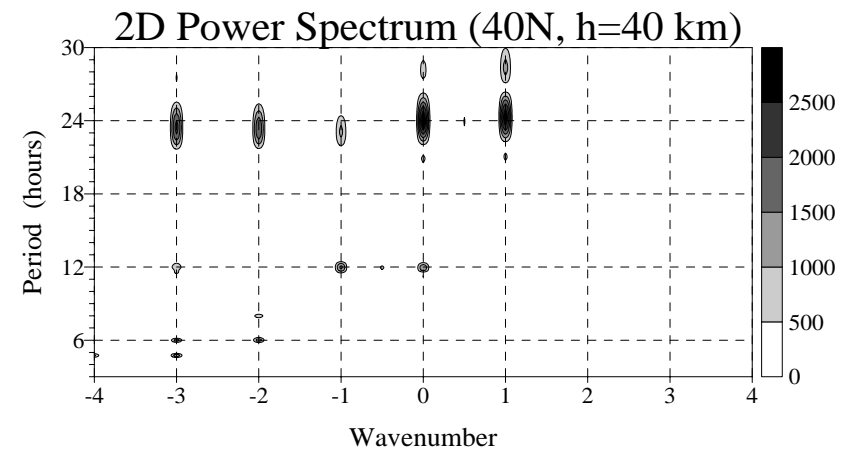

Fig. 3. Two-dimensional power spectrum obtained by a Fourier transform of the two-dimensional autocorrelation function; the spectrum is calculated for the period range $3-30 \mathrm{~h}$ and zonal wave numbers between -4 and 4 from the SABER data for latitude $40^{\circ} \mathrm{N}$ and altitude $40 \mathrm{~km}$ and for the period of time December-January.

procedure has been tested on numerous synthetic time series, representing linear combinations of different waves, before to be used particularly for studying the tides. It is important to note that in the synthetic time series the data sampling patterns have been the same as those of the true SABER measurements. Always the obtained output from the decomposition procedure has been the same as the input. Usually the variations in the zonal mean and the SPWs during winter stratosphere are expected to be much larger than the tidal amplitudes. Therefore an important question is how well the above described data analysis method can characterize the tides in such condition. For this purpose we simulate a time series including the following quantities: (i) variable zonal mean described by a steady zonal mean and a zonally symmetric planetary wave (usually the planetary waves studied by SABER temperatures have periods of 5-30 days), and (ii) amplitude modulated SPW with a given period (that belongs to the planetary waves, 5-30 days) and a coefficient of modulation. We emphasize that the output from the analysis of the above mentioned synthetic time series does not consist any tides. The output is composed of: (i) zonal mean, (ii) zonally symmetric wave, (iii) SPW, and (iv) two zonally propagating in the opposite directions planetary waves with the same amplitudes and zonal wavenumbers and with a period that is equal to the modulating period of the SPW (Mukhtarov et al., 2009b). Additionally, if to the above described synthetic time series a given tide has been included, then the same tide, with the given amplitude and phase is found in the output.

Therefore, by using a least squares fitting technique (to avoid the constraint of sampling uniformity) applied to a 60-day window (to sample $24 \mathrm{~h}$ in local time by combining ascending and descending data together) where the tides and planetary waves are simultaneously extracted from the SABER temperature data the aliasing problems between the variable zonal mean, variable SPWs and tides are fully overcome. We remind that when Gaussian noise is included in the data only because of the data sampling pattern some false diurnal tides with different zonal wavenumbers are generated however their amplitudes do not exceed $1 \mathrm{~K}$.

The spectral analysis indicated that only the nonmigrating diurnal tides are particularly strong in the stratosphere hence only the results for the diurnal tides will be shown here. Figure 4 (left column of panels) presents the altitude-time cross sections at $40^{\circ} \mathrm{N}$ of the following diurnal tidal amplitudes: migrating W1 (a), W2 (b), and zonally symmetric $s=0$ tide (c). In order to facilitate the comparison the nonmigrating W2 and $s=0$ tides have the same scale. The results can be summarized as follows: (i) the migrating 24-h tide amplifies significantly above $100 \mathrm{~km}$ altitude reaching amplitudes of $17 \mathrm{~K}$; it has however mesospheric (centered near 80 and $95 \mathrm{~km}$ height $)$ and stratospheric ( $\sim 50 \mathrm{~km}$ height $)$ amplifications; during December/January, the stratospheric amplification is particularly strong reaching amplitudes of $4-4.5 \mathrm{~K}$; (ii) the W2 and $s=0$ nonmigrating diurnal tides reveal significant amplifications in the lower mesosphere $(\sim 70 \mathrm{~km})$ and stratosphere $(\sim 40 \mathrm{~km})$ during major SSW in December/January; the stratospheric $\mathrm{W} 2$ and $s=0$ nonmigrating diurnal tides at $40 \mathrm{~km}$ altitude have amplitudes larger than those at $90 \mathrm{~km}$, i.e. supporting the results from Fig. 2b; and (iii) the W2 and $s=0$ nonmigrating diurnal tides show also a lower thermospheric amplification with maximum near $110 \mathrm{~km}$.

Nonlinear interactions between stationary planetary waves and migrating tides have been proposed as possible sources of nonmigrating tides in the middle and upper atmosphere (Angelats i Coll and Forbes, 2002). In our case the W2 and $s=0$ nonmigrating diurnal tides can be generated by a nonlinear interaction between the SPW1 and the migrating diurnal tide. The bottom plot (d) of Fig. 4 shows the altitude-time cross sections of the SPW1 amplitude at $40^{\circ} \mathrm{N}$. The temporal evolution and vertical structure of the SPW1 amplitude in the stratosphere and mesosphere are the same with clearly outlined wave maxima near 40 and $70 \mathrm{~km}$; the mesospheric maximum $(9 \mathrm{~K})$ is slightly stronger than the stratospheric one $(8 \mathrm{~K})$. The main amplification is observed in November/December being responsible for the major SSW (late December/January), while the secondary one is centered in the middle of February and it is related to the final SSW. The careful comparison of the SPW1 main amplification (November/December) with those of the migrating and nonmigrating $\mathrm{W} 2$ and $s=0$ tides in the lower mesosphere and stratosphere indicates that they are accomplished concurrently.

Sassi et al. (2002) reported that the double peak vertical temperature structure in the stratosphere and mesosphere shown in panel (d) of Fig. 4 is a consequence of the maintained hydrostatic relation for the vertically propagating planetary waves. This indicates that the temperature perturbation is proportional to the vertical gradient of geopotential perturbation. Climatologically, the geopotential perturbations of quasi-stationary planetary waves maximize at $\sim 60 \mathrm{~km}$ in the winter hemisphere. Their vertical 


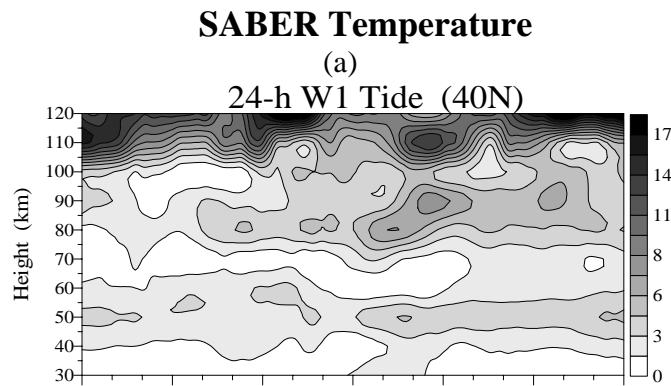

(b)

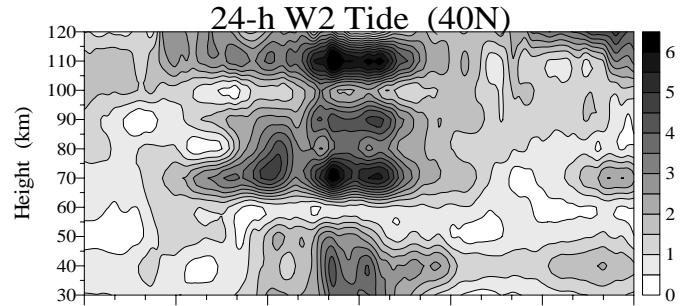

(c)

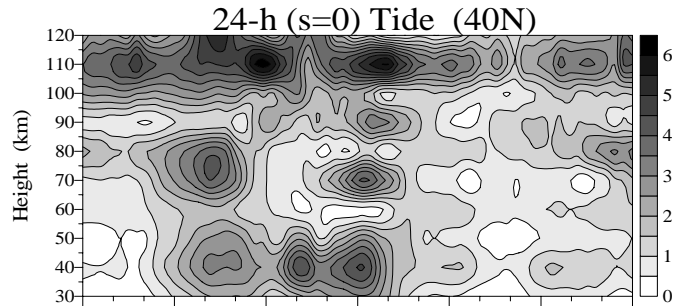

(d)

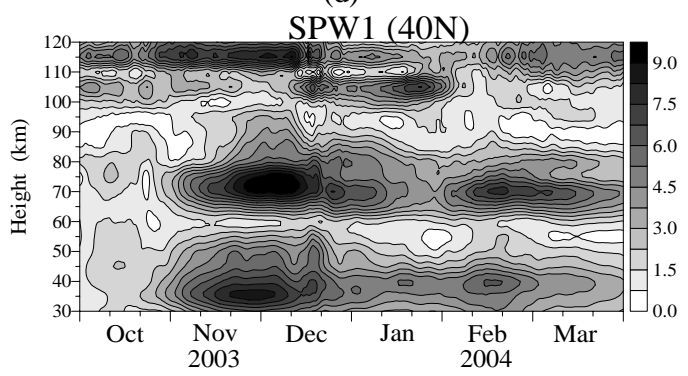

SABER Geopotential Height

(e)

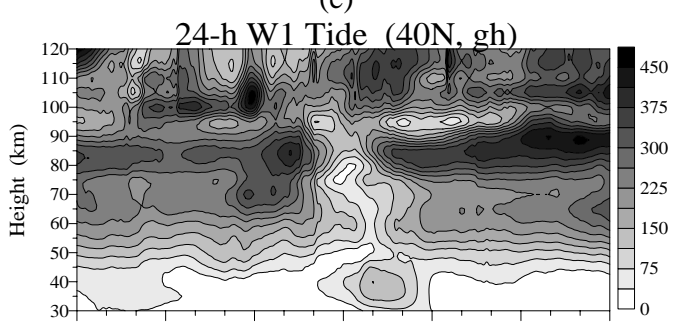

(f)

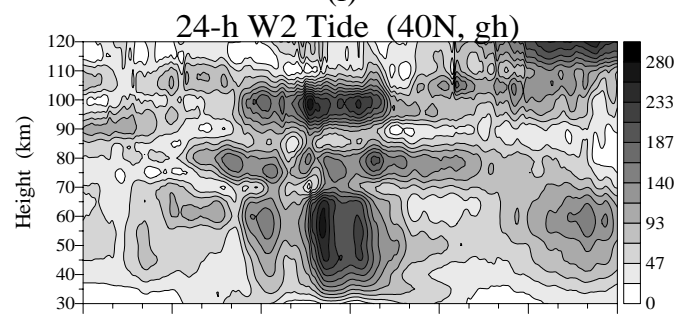

(g)

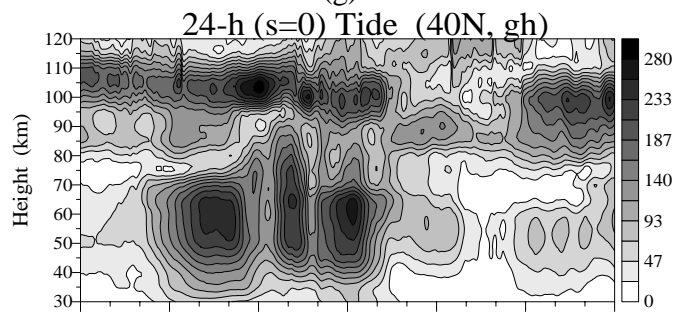

(h)

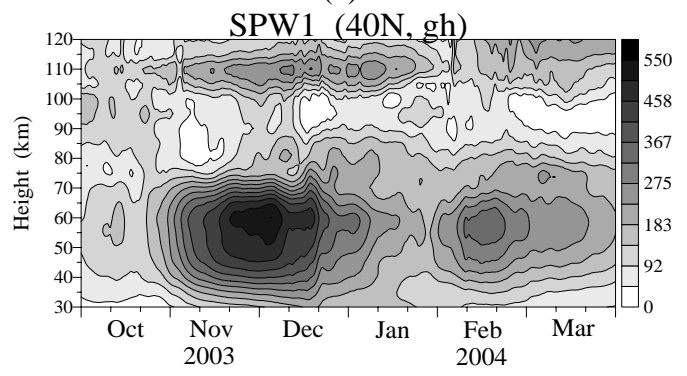

Fig. 4. Altitude-time cross sections of the following amplitudes: migrating W1 tide (a and e), nonmigrating W2 tide (b and f), nonmigrating $s=0$ tide (c and $\mathbf{g}$ ), and SPW1 (d and $\mathbf{h}$ ) seen in the SABER temperatures (left column of plots) and geopotential heights (right column of plot) at $40^{\circ} \mathrm{N}$; the temperature amplitudes are in Kelvin, while those in the geopotential height - in geopotential meters.

gradient, thus the temperature perturbations, maximize below and above $60 \mathrm{~km}$ height and display double peaks. The classical theory of atmospheric tides is also based on the hydrostatic approximations (Chapman and Lindzen, 1970; Kato, 1980). Therefore, the double peak nonmigrating tidal amplifications centered near $40 \mathrm{~km}$ and $70 \mathrm{~km}$ has to be also a consequence of the maintained hydrostatic relation. In order to confirm this assumption the right column of plots in Fig. 4 shows the same wave amplitudes as those in the left column of plots but derived from the SABER geopotential height. The temporal evolutions of the geopotential tides and SPW1 in the stratosphere and mesosphere are very similar to those in the temperature waves but the amplitude maxima take place at the altitudes where the temperature waves have minima.

Figure 5 (left column of plots) presents the altitude-time cross sections at $40^{\circ} \mathrm{N}$ of the migrating W1 (a) tide (the same as that in the Fig. 4) and the nonmigrating W3 (b) and E1 (c) tides. In order to facilitate the comparison again the nonmigrating W3 and E1 tides have the same scale. The plots (b) and (c) reveal that the nonmigrating W3 and E1 amplitudes at $40 \mathrm{~km}$ height are stronger than those at $90 \mathrm{~km}$. This comparison supports the 2-D LS spectral results shown in Fig. $2 b$ (bottom plots). In this case the $\mathrm{W} 3$ and E1 nonmigrating diurnal tides can be generated by a nonlinear interaction between the SPW2 and the migrating diurnal tide. The bottom 


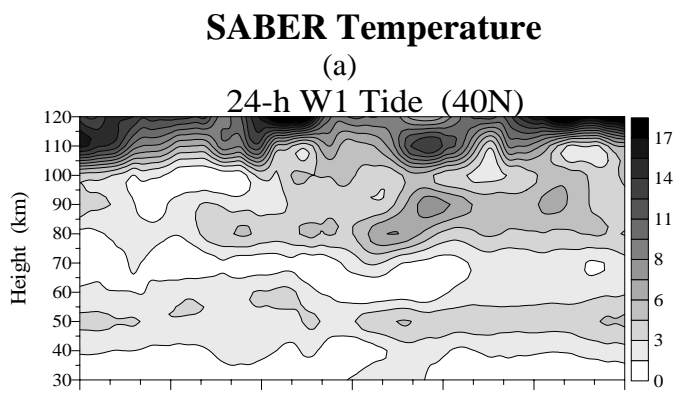

(b)

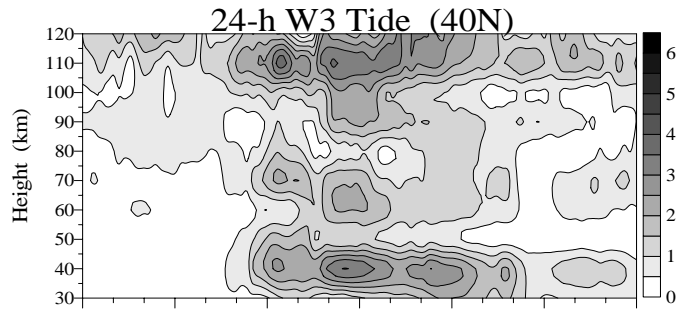

(c)

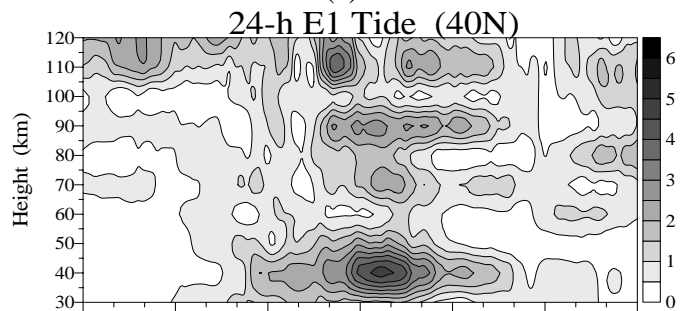

(d)

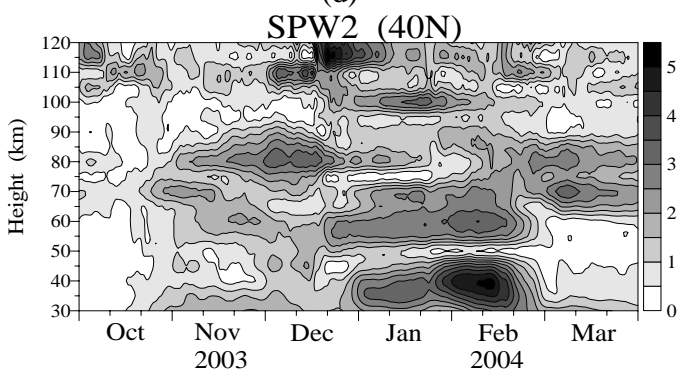

SABER Geopotential Height

(e)

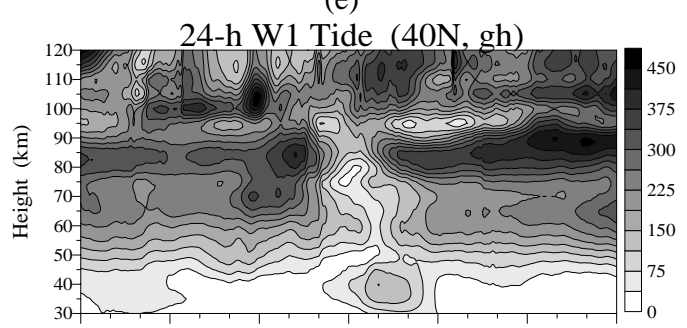

(f)

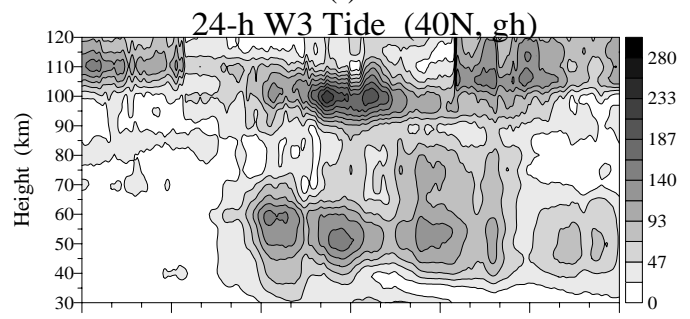

(g)

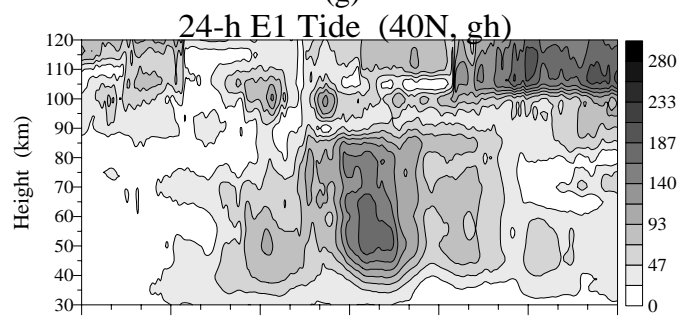

(h)

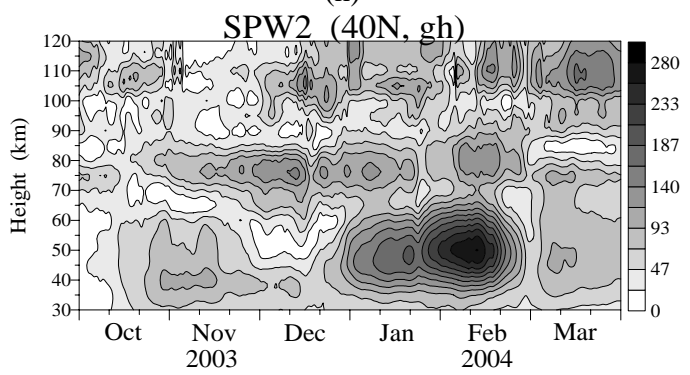

Fig. 5. Altitude-time cross sections of the following amplitudes: migrating W1 tide (a and e), nonmigrating W3 tide (b and f), nonmigrating E1 tide (c and $\mathbf{g}$ ), and SPW2 (d and h) seen in the SABER temperatures (left column of plots) and geopotential heights (right column of plot) at $40^{\circ} \mathrm{N}$.

plot (d) of Fig. 5 shows the altitude-time cross sections of the SPW2 amplitude at $40^{\circ} \mathrm{N}$. The temporal evolution and vertical structure of the SPW2 amplitude in the stratosphere and mesosphere again are very similar with clearly outlined wave maxima near 40 and $60 \mathrm{~km}$, however the stratospheric maximum $(5 \mathrm{~K})$ is stronger than the mesospheric one $(3.5 \mathrm{~K})$. The SPW2 amplification is observed in the period of time between the end of December and the middle of February. A careful comparison of the SPW2 amplification with those of the nonmigrating $\mathrm{W} 3$ and E1 tides in the stratosphere and lower mesosphere indicates again that they occur concurrently. Similarly to the SPW2 the nonmigrating W3 and E1 tidal amplitudes in the stratosphere are larger than those in the mesosphere.
In order to demonstrate that the stratospheric and lower mesospheric amplifications of the nonmigrating diurnal W3 and E1 tides are real and that they are a result from the hydrostatic relation the right column of plots in Fig. 5 shows the same wave amplitudes as those in the left column of plots but derived from the SABER geopotential height. Again as in Fig. 4 the temporal evolutions of the geopotential tides and SPW2 in the stratosphere and lower mesosphere are very similar to those in the temperature waves but the amplitude maxima take place at the altitudes where the temperature waves have minima.

It has been already mentioned that the TIMED is approximately a Sun-synchronized satellite. The local time precession periods bring to light the major shortcomings 

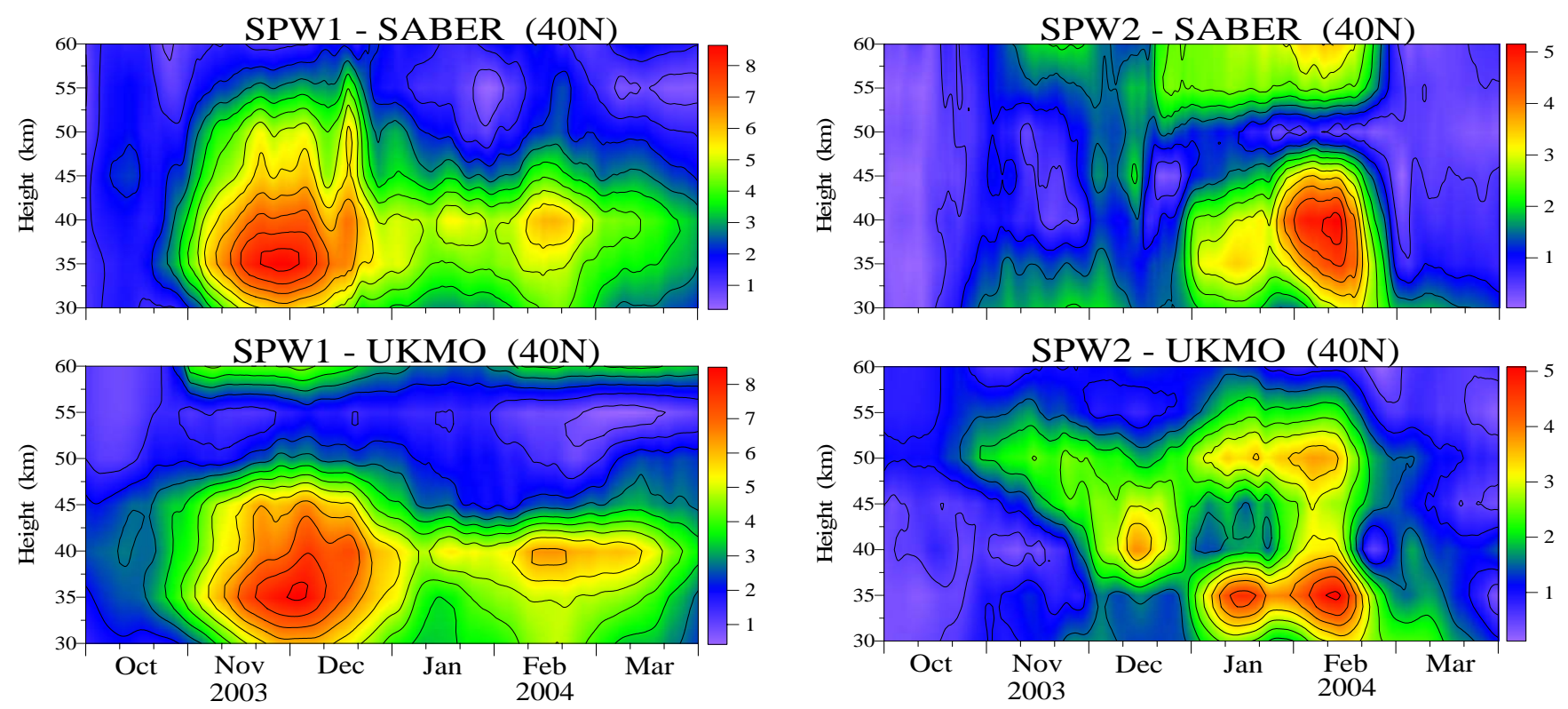

Fig. 6. Altitude-time cross sections of the SPW1 (left column of plots) and SPW2 (right column of plots) amplitudes seen in the SABER temperatures (upper row of plots) and UKMO assimilated temperature data (bottom row of plots) at $40^{\circ} \mathrm{N}$ and in the altitude range between 30 and $60 \mathrm{~km}$.

of using satellite-based measurements to derive atmospheric tides (Forbes et al., 2006). As it has been mentioned before the evolution of the migrating tides aliases into the derived zonal mean temperature when we use a time window less than 60 days (see the discussion about the left plot of Fig. 1). In a similar way, the temporal variation of the SPWs can alias into the non-migrating tides. This aliasing effect however is expected to ultimately disappear when all local times are sampled at all longitudes, i.e. when a 60-day window is used to derive the waves from the SABER/TIMED temperatures. We have to note also that an important advantage of the data analysis method used here is that the tides and the planetary waves (zonally travelling and stationary) are simultaneously extracted from the satellite data. This is another significant step in minimizing the aliasing effects between the tides and SPWs.

In order to demonstrate that the derived SABER SPW1 and SPW2 are not affected by aliasing effects we compare their altitude-time structures in the stratosphere with those derived from the daily UKMO temperature data at $40^{\circ} \mathrm{N}$. The derived UKMO SPWs are not affected by aliasing because the data are evenly distributed in time and space. The left column of plots in Fig. 6 shows the amplitudes of the SPW1, while the right one - those of the SPW2; at the upper row of plots are presented the SABER amplitudes, while at the bottom one are the UKMO amplitudes. The comparison between the amplitudes of the SABER and UKMO SPW1 (left column of plots) is excellent. The main amplification at both data sets is centered at $35 \mathrm{~km}$ height in the end of November and its maximum amplitude is $8 \mathrm{~K}$. The SABER and UKMO amplitudes of the SPW2 (right column of plots) are also quite similar, particularly in the middle stratosphere $(35-40 \mathrm{~km}$ height) where the maximum amplitude seen in both data sets is $5 \mathrm{~K}$. These results indicate that the nonmigrating diurnal tides, particularly $\mathrm{W} 2, s=0, \mathrm{~W} 3$ and E1, extracted from the SABER temperatures are not affected by aliasing effects from the SPW1 and SPW2.

\subsection{Latitude tidal structure}

Figure 7a shows the latitude-time cross sections (from $50^{\circ} \mathrm{N}$ to $50^{\circ} \mathrm{S}$ ) of the nonmigrating diurnal W2 (upper left plot) and $s=0$ (bottom left plot) tidal amplitudes at $40 \mathrm{~km}$ and $70 \mathrm{~km}$ altitudes. The nonlinear interaction between the migrating W1 diurnal tide and the SPW1 has been proposed as a source of the above mentioned nonmigrating tides in the middle atmosphere. Their amplitudes in the stratosphere $(40 \mathrm{~km})$ and lower mesosphere $(70 \mathrm{~km})$ are shown at the upper right and bottom right plots respectively. The right column of plots clearly indicates that the nonmigrating $\mathrm{W} 2$ and $s=0$ tides are present only in the Northern Hemisphere (NH) and their amplitudes grow with increasing latitude; while at $40^{\circ} \mathrm{N}$ their amplitudes reach $5-6 \mathrm{~K}$, at $50^{\circ} \mathrm{N}$ they reach $8 \mathrm{~K}$. The main amplifications of these nonmigrating tides are in the period of time between the middle of November 2003 and the end of January (near days 40-120), when the activity of the SPW1 (bottom right plot) is particularly strong. Some signature of the nonmigrating $\mathrm{W} 2$ tide can be distinguished over the equator in the lower mesosphere $(70 \mathrm{~km})$. A possible reason could be related to the existence of a much stronger migrating tide 

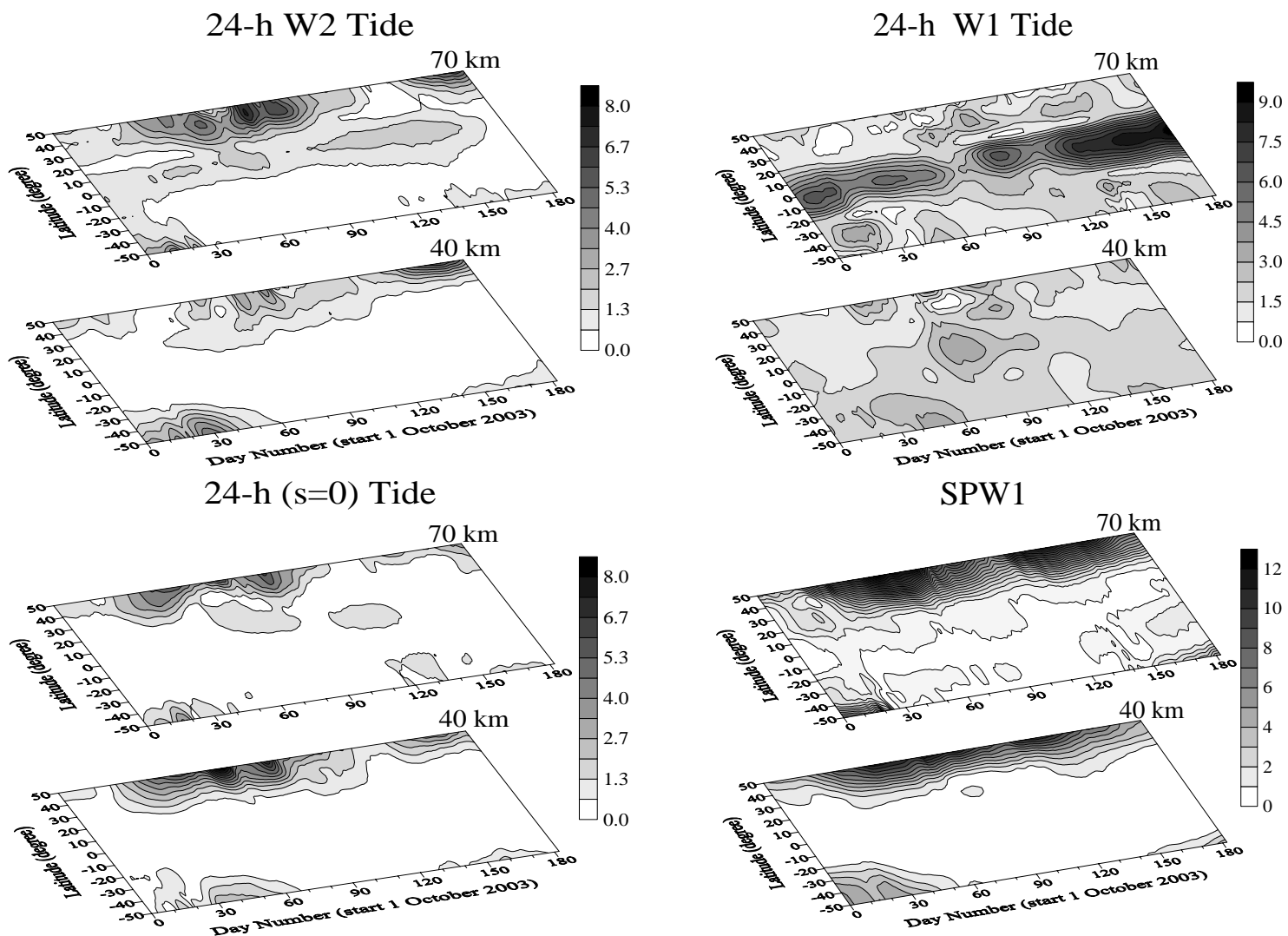

Fig. 7a. Latitude-time cross sections (from $50^{\circ} \mathrm{N}$ to $50^{\circ} \mathrm{S}$ ) of the following amplitudes: nonmigrating W2 tide (upper left plot), nonmigrating $s=0$ tide (bottom left plot), migrating W1 tide (upper right plot) and SPW1 (bottom right plot) at altitudes of $40 \mathrm{~km}$ and $70 \mathrm{~km}$.

in the lower mesosphere than in the stratosphere and because of some penetration of the SPW1 to the tropical latitudes at mesospheric levels.

Figure $7 \mathrm{~b}$ shows the latitude-time cross sections of the nonmigrating diurnal W3 (upper left plot) and E1 (bottom left plot) tidal amplitudes at $40 \mathrm{~km}$ and $70 \mathrm{~km}$ altitudes. The nonlinear interaction between the migrating $\mathrm{W} 1$ diurnal tide and the SPW2 has been proposed as a source of the above mentioned nonmigrating tides, hence in the right column of plots their respective amplitudes are shown. Similarly to the previous case the nonmigrating $\mathrm{W} 3$ and $\mathrm{E} 1$ tides are observed only in the $\mathrm{NH}$, however their amplitudes increase with increasing latitudes is smaller than that of the W2 and $s=0$ tides. While at $40^{\circ} \mathrm{N}$ their amplitudes reach $5-6 \mathrm{~K}$, at $50^{\circ} \mathrm{N}$ they reach $7 \mathrm{~K}$. The tidal amplitudes are enhanced concurrently with that of the SPW2 as the stratosphere nonmigrating activity is stronger than that in the lower mesosphere.

The clear associations observed in Fig. 7a and $\mathrm{b}$ between the latitude structures of the nonmigrating 24-h tides observed in the NH stratosphere and lower mesosphere from one side and the migrating diurnal tide and the SPW1 and SPW2 from the other side present additional evidence for the SPW-migrating tide interaction as a source of nonmigrating tides.

\section{Summary}

The main focus of this paper was to study the nonmigrating tidal activity seen in the SABER/ TIMED temperatures and possibly related to the major SSW in the Arctic winter of $2003 / 2004$. The disturbed period of time related to the major SSW was distinguished by considering the zonal mean SABER temperatures shown in Fig. 1 (left plot), where the disturbed time interval of December/January was clearly outlined.

The emphasis was on the tidal activity observed in the stratosphere and lower mesosphere which is usually accepted to be insignificant in comparison with that in the upper mesosphere and thermosphere. A new method for defining the reference noise level of the tidal waves has been described. This problem is very important for the tidal assessment when they are derived from the satellite data. This is based on the fact that only because of the satellite data sampling pattern and the wave variability during the 60-day windows used for extracting the tides from the data false diurnal tides with different zonal wavenumbers are generated (see Fig. 2a) Actually, this is the aliasing problem in our case where the tides and the planetary waves are simultaneously extracted from the satellite data. All results presented in this study are based only 

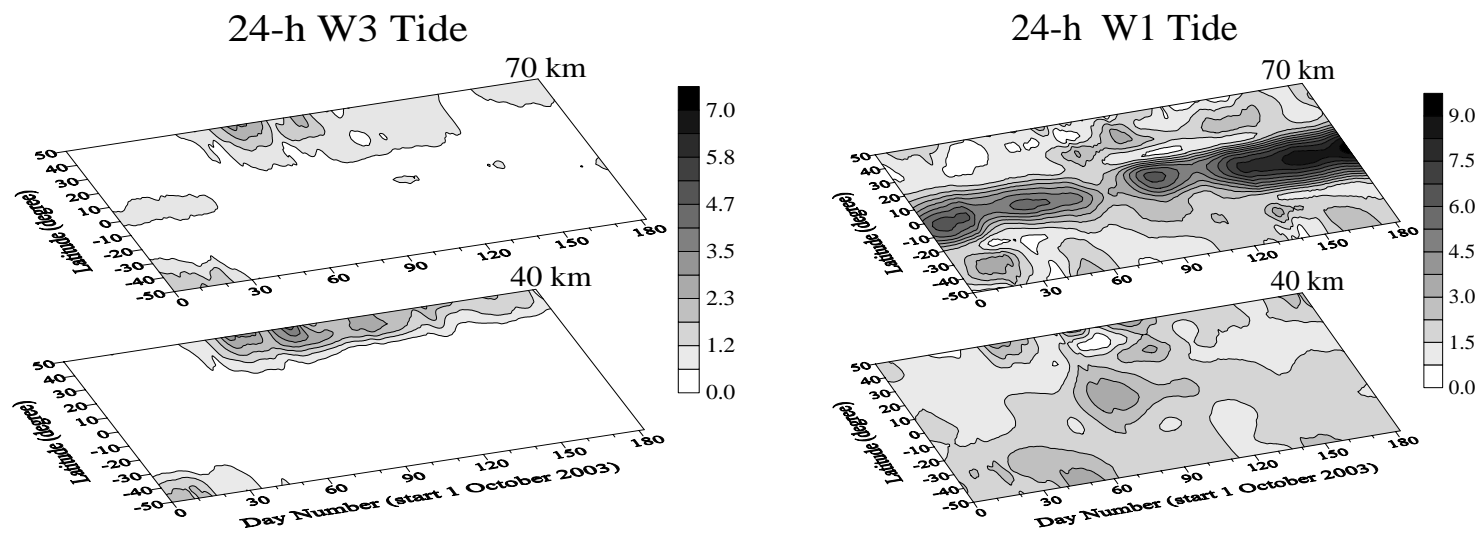

24-h E1 Tide
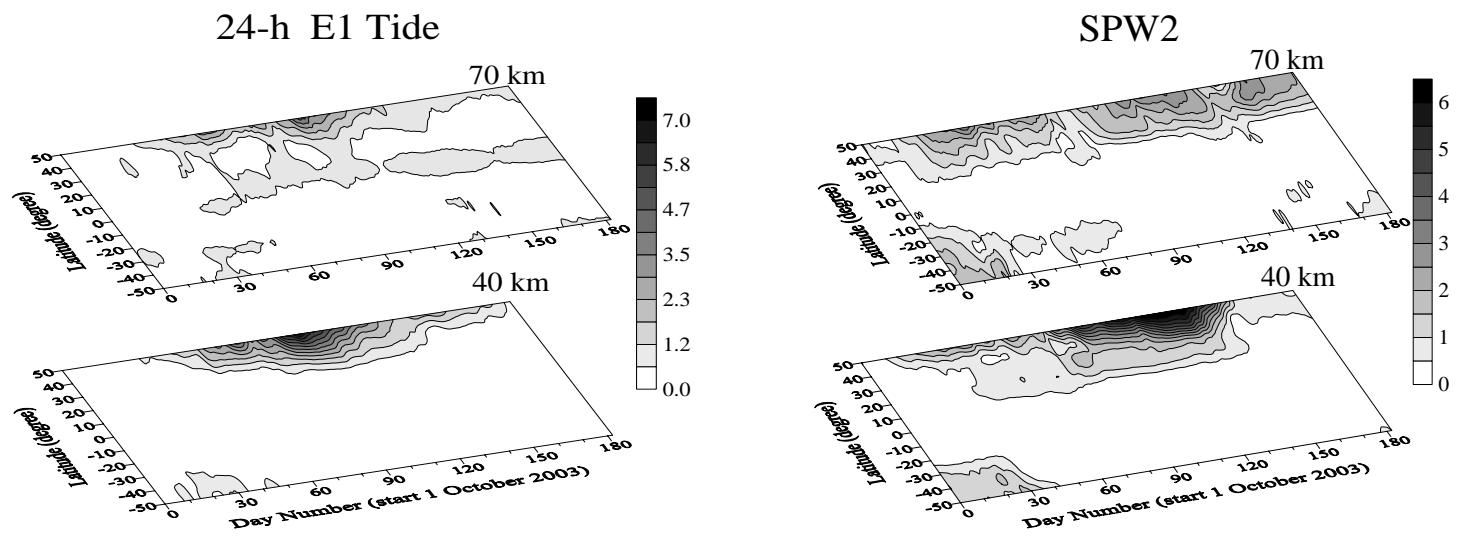

Fig. 7b. Latitude-time cross sections of the following amplitudes: nonmigrating W3 tide (upper left plot), nonmigrating E1 tide (bottom left plot), migrating W1 tide (upper right plot) and SPW2 (bottom right plot) at altitudes of $40 \mathrm{~km}$ and $70 \mathrm{~km}$.

on statistically significant temperature tides (with amplitudes larger than $1 \mathrm{~K}$ ) derived from the SABER measurements.

Two types of spectral analysis were performed on the SABER data: 2-D (time-longitude) LS periodogram method and 2-D (time-longitude) power spectrum obtained by a Fourier transform of the 2-D autocorrelation function. The second method is not well known and its brief description was included as well. The two independent spectral methods applied to the SABER data at $40^{\circ} \mathrm{N}$ latitude and $40 \mathrm{~km}$ altitude for the disturbed time interval December-January revealed the same result (see Figs. $2 b$ and 3 ), which consists of a significant amplification of the following nonmigrating 24-h tides: zonally symmetric $(s=0), \mathrm{E} 1, \mathrm{~W} 2$ and W3 tides. Using different independent methods and obtaining the same results is an important evidence for the validity of these results.

An important step in this study was the simultaneous extraction of tides and planetary waves from the satellite data. In this way a possible distortion of the weaker waves by the stronger ones, as well as some aliasing effects between tides and SPWs were avoided. We remind that the numerous examinations of the data analysis method applied on synthetic time series with data sampling patterns the same as the true SABER measurements unambiguously demon- strated that the output results are always the same as the input ones. The waves were extracted by using a linear twodimensional (time-longitude) least-squares fitting procedure applied to a 60-day window (because it takes SABER 60 days to sample $24 \mathrm{~h}$ in local time) which was moved through the time series with steps of 1 day in order to obtain daily values of the wave characteristics. Regardless of using a long time segment (60 days) for evaluation of the tidal characteristics the sliding procedure gives a chance the tidal variability of a month time-scale and even less to be detected. In this way it has been found that the nonmigrating diurnal tidal activity amplifies significantly in December/January when the major SSW takes place.

By comparing the altitude and latitude structures of the nonmigrating (W3, W2, $s=0$ and E1) diurnal tides with those of the migrating diurnal tide and SPWs (Figs. 4, 5, 7a and 7b) we documented evidence for the SPW-migrating tide interaction as a source of nonmigrating tides. An important result is that the found double peak nonmigrating tidal amplifications centered near $40 \mathrm{~km}$ and $70 \mathrm{~km}$ are a consequence of the maintained hydrostatic relation. Therefore, if the nonmigrating temperature tides are seen in the lower mesosphere (Lieberman et al., 2004) most probably they should be present in the stratosphere as well. 
In order to demonstrate that the SABER SPW1 and SPW2 amplitudes are not affected by aliasing effects we compared them with those derived from the UKMO assimilated temperature data at $40^{\circ} \mathrm{N}$. The agreement between the two and particularly for the SPW1 is excellent (Fig. 6). As the UKMO SPWs are not affected by aliasing this means that there are no aliasing effects between the SABER SPWs and the considered nonmigrating diurnal tides.

In conclusion, we note that by investigating the tidal activity seen in the SABER temperatures it was found a significant amplification of some nonmigrating 24-h (zonally symmetric, E1, W2 and W3) tides in the stratosphere and lower mesosphere closely related to the major SSW observed in the Arctic winter of 2003/2004. By detailed comparison of the evolution and spatial structure of the nonmigrating diurnal tides with those of the migrating tide and SPWs it has been presented evidence for the SPW-migrating tide interaction as a source of nonmigrating tides. Therefore, the nonmigrating 24-h tides turn out to be an important component of the middle atmosphere dynamics during the major SSW in the Arctic winter of 2003/2004.

Acknowledgements. We are grateful to the SABER team for the access to the data on http://saber.gats-inc.com and to the UKMO and the BADC for the access to the data on http://www.badc.rl.ac. $\mathrm{uk} / \mathrm{data} / \mathrm{assim}$. One of the authors, DP, is particularly thankful to A. Smith for clarifying some details about the SABER data. We thank C. Jacobi and the other anonymous reviewer for their insightful comments on the original manuscript.

Topical Editor K. Kauristie thanks C. Jacobi and another anonymous referee for their help in evaluating this paper.

\section{References}

Angelats i Coll, M. and Forbes, J. M.: Nonlinear interactions in the upper atmosphere: The $s=1$ and $s=3$ nonmigrating semidiurnal tides, J. Geophys. Res., 107, A8, doi:10.1029/2001JA900179, 2002

Azeem, S. M. I., Talaat, E. R., Sivjee, G. G., Liu, H.-L., and Roble, R. G.: Observational study of the 4-day wave in the mesosphere preceding the sudden stratospheric warming events during 1995 and 2002, Geophys. Res. Lett., 32, L15804, doi:10.1029/2005GL023393, 2005.

Chapman, S. and Lindzen, R.: Atmospheric Tides; Thermal and Gravitational, Gordon \& Breach, New York, 1970.

Coy, L., Siskind, D. E., Eckermann, S. D., McCormack, J. P., Allen, D. R., and Hogan, T. F.: Modeling the August 2002 minor warming event, Geophys. Res. Lett., 32, L07808, doi:10.1029/2005GL022400, 2005.

Forbes, J. M., Russell, J., Miyahara, S., Zhang, X., Palo, S., Mlynczak, M., Mertens, C. J., and Hagan, M. E.: Tropospherethermosphere tidal coupling as measure by the SABER instrument on TIMED during July-September 2002, J. Geophys. Res., 111, A10S06, doi:10.1029/2005JA011492, 2006.

García-Comas, M., Lopez-Puertas, M., Marshall, B. T., Wintersteiner, P. P., Funke, B., Bermejo-Pantaleon, D., Mertens, C. J., Remsberg, E. E., Gordley, L. L., Mlynczak, M. G., and Rus- sell, J. M.: Errors in Sounding of the Atmosphere using Broadband Emission Radiometry (SABER) kinetic temperature caused by non-local-thermodynamic-equilibrium model parameters, J. Geophys. Res., 113, D24106, doi:10.1029/2008JD010105, 2008.

Hoffmann, P., Singer, W., Keuer, D., Hocking, W., Kunze, D., and Murayama, Y.: Latitudinal and longitudinal variability of mesospheric winds and temperatures during stratospheric warming events, J. Atmos. Sol.-Terr. Phys., 69, 2355-2366, 2007.

Jacobi, C., Kürschner, D., Muller, H. G., Pancheva, D., Mitchell, N. J., and Naujokat, B.: Response of the mesopause region dynamics to the February 2001 stratospheric warming, J. Atmos. Sol.-Terr. Phys., 65, 843-855, 2003.

Kato, S.: Dynamics of the upper atmosphere, D. Reidel Publishing Company/Dordrecht, Boston, 1980.

Kong, A. K. H., Charles, P. A., and Kuulkers, E.: Long-term X-ray variability in GX 354-0, New Astronomy, 3(5), 301-307, 1998.

Lieberman, R., Oberheide, J., Hagan, M., Remsberg, E., and Gordley, L.: Variability of diurnal tides and planetary waves during November 1978-May 1979, J. Atmos. Sol.-Terr. Phys., 66, 517528, 2004.

Liu, H.-L. and Roble, R. G.: A study of a self-generated stratospheric sudden warming and its mesospheric-lower thermospheric impacts using the coupled TIME-GCM/CCM3, J. Geophys. Res., 107(D23), 4695, doi:10.1029/2001JD001533, 2002.

Liu, H.-L. and Roble, R. G.: Dynamical Coupling of the stratosphere and mesosphere in the 2002 Southern Hemisphere major stratospheric sudden warming, Geophys. Res. Lett., 32, L13804, doi:10.1029/2005GL022939, 2005.

Lomb, N. R.: Least-squares frequency analysis of unequally spaced data, Astrophys. Space Sci., 39, 447-462, 1975.

Manney, G. L., Krüger, K., Sabutis, J. L., Sena, S. A., and Pawson, S.: The remarkable 2003-2004 winter and other recent warm winters in the Arctic stratosphere since the late 1990s, J. Geophys. Res., 110, D04107, doi:10.1029/2004JD005367, 2005.

Matsuno, T.: A dynamical model of the stratospheric sudden warming, J. Atmos. Sci., 28, 1479-1494, 1971.

Mertens, C. J., Mlynczak, M., Lopez-Puertas, M., et al.: Retrieval of mesospheric and lower thermospheric kinetic temperature from measurements of $\mathrm{CO}_{2} 15 \mu \mathrm{m}$ earth limb emission under nonLTE conditions, Geophys. Res. Lett., 28, 1391-1394, 2001.

Mertens, C. J., Schmidlin, F. J., Goldberg, R. A., et al.: SABER observations of mesospheric temperature and comparisons with falling sphere measurements taken during the 2002 summer MaCWINE campaign, Geophys. Res. Lett., 31, J03105, doi:10.1029/2003GL018605, 2004.

Mukhtarov, P., Pancheva, D., Andonov, B., Mitchell, N. J., Singer, W., Hocking, W., Manson, A., Meek, C., Murayama, Y., and Merzlyakov, E.: Large-scale thermodynamics of the stratosphere and mesosphere during the major stratospheric warming in 2003/2004, J. Atmos. Sol-Terr. Phys., 69, 2338-2354, 2007.

Mukhtarov, P., Pancheva, D., and Andonov, B.: Global structure and seasonal and interannual variability of the migrating diurnal tide seen in the SABER/TIMED temperatures between 20 and $120 \mathrm{~km}$, J. Geophys. Res., 114, A02309, doi:10.1029/2008JA013759, 2009a.

Mukhtarov, P., Pancheva, D., and Andonov, B.: Method for assessing the amplitude modulation of the stationary planetary waves, Ann. Geophys., 27, 617-622, 2009b, http://www.ann-geophys.net/27/617/2009/. 
Palo, S. E., Forbes, J. M., Zhang, X., Russell, J. M., Mertens, C. J., Mlynczak, M. G., Burns, G. B., Espy, P. J., and Kawahara, T. D.: Planetary wave coupling from the stratosphere to the thermosphere during the 2002 Southern Hemisphere pre-stratwarm period, Geophys. Res. Lett., 32, L23809, doi:10.1029/2005GL0242298, 2005.

Pancheva, D. V., Mukhtarov, P. J., and Andonov, B. A.: Zonally symmetric oscillations in the Northern hemisphere stratosphere during the winter of 2003/2004, Geophys. Res. Lett., 34, L04807, doi:10.1029/2006GL028666, 2007.

Pancheva, D., Mukhtarov, P., Mitchell, N. J., Merzlyakov, E., Smith, A. K., Andonov, B., Singer, W., Hocking, W., Meek, C., Manson, A., and Murayama, Y.: Planetary Wave Coupling of the Stratosphere and Mesosphere during the Major Stratospheric Warming in 2003/2004, J. Geophys. Res., 113, D12105, doi:10.1029/2007JD009011, 2008a.

Pancheva, D., Mukhtarov, P., Mitchell, N. J., Andonov, B., Merzlyakov, E., Singer, W., Murayama, Y., Kawamura, S., Xiong, J., Wan, W., Hocking, W., Fritts, D., Riggin, D., Meek, C., and Manson, A.: Latitudinal wave coupling of the stratosphere and mesosphere during the major stratospheric warming in 2003/2004, Ann. Geophys., 26, 467-483, 2008b, http://www.ann-geophys.net/26/467/2008/.

Pancheva, D., Mukhtarov, P., Andonov, B., Mitchell, N. J., and Forbes, J. M.: Planetary waves observed by TIMED/SABER in coupling the stratosphere-mesosphere-lower thermosphere during the winter of 2003/2004: Part 1, Comparison with the UKMO temperature results, J. Atmos. Sol.-Terr. Phys., 71, 61-74, 2009a.

Pancheva, D., Mukhtarov, P., Andonov, B., Mitchell, N. J., and Forbes, J. M.: Planetary waves observed by TIMED/SABER in coupling the stratosphere-mesosphere-lower thermosphere during the winter of 2003/2004: Part 2, Altitude and latitude planetary wave structure, J. Atmos. Sol.-Terr. Phys., 71, 75-87, 2009 b.
Pancheva, D., Mukhtarov, P., and Andonov, B.: Global structure, seasonal and interannual variability of the migrating semidiurnal tide seen in the SABER/TIMED temperatures (2002-2007), Ann. Geophys., 27, 687-703, 2009c, http://www.ann-geophys.net/27/687/2009/.

Remsberg, E. E., Marshall, B. T., García-Comas, M., Krueger, D., Lingenfelser, G. S., Martin-Torres, J., Mlynczak, M. G., Russell, J. M., Smith, A. K., Zhao, Y., Brown, C., Gordley, L. L., LopezGonzales, M. J., Lopez-Puertas, M., She, C.-Y., Taylor, M. J., and Thompson, R. E.: Assessment of the quality of the Version 1.07 temperature-versus-pressure profiles of the middle atmosphere from TIMED/SABER, J. Geophys. Res., 113, D17101, doi:10.1029/2008JD0100113, 2008.

Russell III, J. M., Mlynczak, M. G., Gordley, L. L., Tansock, J., and Esplin, R.: An overview of the SABER experiment and preliminary calibration results, Proceedings of the SPIE, 44th Annual Meeting, Denver, Colorado, 18-23 July, vol. 3756, pp. 277-288, 1999.

Sassi, F., Garcia, R. R., Boville, B. A., and Liu, H.: On temperature inversions and the mesospheric surf zone, J. Geophys. Res., 107(D19), 4380, doi:10.1029/2001JD001525, 2002.

Scargle, J. D.: Studies in astronomical time series analysis. II. Statistical aspects of spectral analysis of unevenly spaced data, Astrophys. J., 263, 835-853, 1982.

Shepherd, M. G., Wu, D. L., Fedulina, I. N., Gurubaran, S., Russell, J. M., Mlynczak, M. G., and Shepherd, G. G.: Stratospheric warming effects on the tropical mesospheric temperature field, Atmos. Sol.-Terr. Phys., 69, 2309-2337, 2007.

Teske, R. G.: Two-dimensional spatial power spectra of photospheric velocity fluctuations, Sol. Phys., 39, 363-375, 1974. 